\title{
1 Soybean meal induces enteritis in turbot Scophthalmus maximus at high 2 supplementation levels
}

3

$4 \quad$ Min Gu $^{a^{*}}$, Nan Bai ${ }^{\text {a }}$, Yanqi Zhang ${ }^{\text {a,c }}$, Åshild Krogdahl ${ }^{\text {b }}$

5

$6 \quad{ }^{\text {a }}$ Marine College, Shandong University, Weihai 264209, China

$7 \quad{ }^{b}$ Department of Basic Sciences and Aquatic Medicine, School of Veterinary Medicine, Norwegian

8 University of Life Sciences (NMBU), N-0033 Oslo, Norway

$9 \quad{ }^{\mathrm{c}}$ State Key Laboratory of Microbial Technology, Shandong University, Jinan 250100, China

10

$11 *$ Corresponding author

12 Min $\mathrm{Gu}$

13 Marine College, Shandong University, Weihai 264209, China

14 Telephone: $+86-631-5677365$

15 Fax: +86-631-5688303

16 E-mail address: gumin@sdu.edu.cn

17 


\begin{abstract}
The goal of the present study was to find whether higher soybean meal (SBM) levels might trigger soybean meal-induced enteritis (SBMIE) in turbot. If so, caution must be taken when mixing ingredients containing saponins and other antinutrients to avoid SBMIE like symptoms. In a 8 week feeding trial conduced on turbot, three isonitrogenous and isolipidic diets were formulated to include $26 \%, 40 \%$ and $54 \%$ SBM to progressively replace $30 \%, 45 \%$ and $60 \%$ fish meal (FM) in a FM based diet, respectively. The results showed that SBM caused dose-dependent decreases in growth performance and nutrient utilization. Enteritis developed in the distal intestine in the inclusion range of 26-54\%. Dose-dependent increases in severity of the inflammation, with concomitant alterations in brush border membrane enzymes and inflammatory marker genes expression were seen. Our results confirm the hypothesis that high inclusion level of SBM may cause similar inflammatory changes as observed in several other fish species. Thus, caution must be taken when formulating turbot diets based on ingredients that may contain saponins and other antinutrients. Moreover, turbot is also a candidate species for the study of causes and mechanism of diet induced inflammation in the intestine of fish.
\end{abstract}

Keyword: inflammation; intestine; soybean meal; turbot 


\section{Introduction}

Turbot Scophthalmus maximus has become the most important cultured flatfish in Europe and Asia because of its high quality flesh and rapid growth, with a global production of around 70000 $\mathrm{t}$ per year (FAO FishStatJ 2013). Global aquaculture has continued to grow while the production of fish meal is stable, at best. Thus, research on alternatives to fish meal has been an international priority for more than two decades (Hardy and Kissil, 1997). Among the ingredients investigated as alternatives to fish meal, soy products are some of the most promising because of the security of supply, price and good reasonable amino acid profile (Storebakken et al., 2000). However, soybean meal (SBM) of standard quality is used in carnivorous fish diets only at relatively low levels due to its negative effects on gut health in several fish species (Krogdahl et al., 2010; Merrifield et al., 2011). Specifically, soybean meal has been observed to cause proliferative or inflammatory conditions in the distal intestinal mucosa of cultured fish species such as Atlantic salmon, rainbow trout, common carp and zebra fish (van den Ingh et al., 1991; Rumsey et al., 1994; Baeverfjord and Krogdahl, 1996; Yamamoto et al., 2008; Urán et al., 2008; Hedrera et al., 2013). The histopathological changes, commonly referred to as soybean meal-induced enteritis (SBMIE), have been extensively studied, and are characterized by a shortening of the mucosal folds, a swelling of the lamina propria and subepithelial mucosa, a strong infiltration of various inflammatory cells, and decreased numbers of absorptive vacuoles in the enterocytes, a situation that decrease the capacity of the distal intestine to digest and absorb nutrients (van den Ingh et al., 1991; Baeverfjord and Krogdahl, 1996; Bakke-McKellep et al., 2000; Bakke-McKellep et al., 2007). In Atlantic salmon, the effects of SBM were proved to be dose-dependent; the worst symptoms were observed at the highest inclusion level $(30 \%)$, but even the lowest evaluated amount of SBM (10\%) generated adverse effects in salmon (Krogdahl et al., 2003). The key antinutrient responsible for the enteritis was recently confirmed to be saponins (Krogdahl et al., 2015). Based on research conducted by Bonaldo et al (2011) on turbot juveniles, turbot appear insensitive to SBM, at least up to $22 \%$ in the diet, a level which was found not to affect the digestibility and intestinal histology. As saponins may be supplied also by other plant feed ingredients and in total reach high levels, there is a need to investigate whether SBM might induce enteritis in turbot when included at levels higher than $22 \%$.

Recent studies in Atlantic salmon have described the SBMIE at the transcriptional level, which is characterized by induction of acute inflammatory-related cytokines and chemokines, NF-KB and TNF-a related genes and regulators of B and T lymphocytes function (Skugor et al., 2011; Sahlmann et al., 2013; Grammes et al., 2013; De Santis et al., 2015). To our knowledge, no studies have been reported to investigate the molecular mechanisms on SBMIE in turbot. The purpose of this study was to investigate whether the high inclusion level of SBM in the range of 26-54\% may affect nutrient utilization, digestibility and induce enteritis in turbot. To further elucidate mechanisms leading to the development of SBMIE, the present study examined the expression of genes related to inflammatory responses (qPCR).

\section{Materials and methods}

\subsection{Feed ingredients and diet formulation}

Based on Yun et al. (2012), a basal diet (named as FM) were formulated to contain 48\% crude protein and $12 \%$ crude lipid with fish meal as the primary protein source, fish oil and soybean oil as lipid source and wheat flour as the carbohydrate source. This diet was used as 
control. Based on the FM diet (control diet), another three isonitrogenous and isolipidic diets were formulated to contain $260 \mathrm{~g} \mathrm{~kg}^{-1}, 400 \mathrm{~g} \mathrm{~kg}^{-1}$ and $540 \mathrm{~g} \mathrm{~kg}^{-1}$ soybean meal as replacement of $30 \%$, $45 \%$ and $60 \%$ fish meal in the basal diet, named as SBM26, SBM40 and SBM54, respectively (Table 1). As list in Table 2, all four diets could meet the essential amino acid (EAA) requirements of juvenile turbot based on the whole body amino acid profile (Kaushik, 1998; Peres and Oliva-Teles, 2008), no crystalline amino acids were supplemented. The diets preparation and storage were as described by Yun et al. (2012).

\subsection{Experimental procedure}

Disease-free juvenile turbot were obtained from a commercial farm in Haiyang, China and transferred to an indoor flow-through water system in the Haiyang Yellow Sea Aquatic Product Co., Ltd. Fish were acclimated to the system and fed with the FM diet for 2 weeks. After that, turbot with initial body weight of about $8.5 \mathrm{~g}$ were randomly distributed into 12 tanks, 30 fish per tank (filled with $300 \mathrm{~L}$ seawater). The seawater was pumped from coast adjacent, filtered through a sand filter and distributed to each tank at approximate $2.0 \mathrm{~L} / \mathrm{min}$. Each diet was fed to fish in three tanks. Fish were fed with the experimental diets to apparent satiation twice daily at 07:00 and 18:00. During the 8-week feeding trial, water temperature was $12-16{ }^{\circ} \mathrm{C}, \mathrm{pH} 7.8-8.2$ and salinity 28-30.

2.3 Sampling

The fish were weighed at start and at end of the experiment. After 8 weeks of feeding, six fish per tank were randomly selected and their body weight and length were recorded. Then, the fish were killed by a sharp blow to the head and the ventral belly surface was opened to expose the abdominal cavity. Only fish with digesta throughout the intestinal tract were sampled to ensure intestinal exposure to the diets. The intestine and liver were removed, cleared of any mesenteric, adipose tissue, rinsed with ice-cold distilled water to remove the eventual remaining gut contents and weighed. Sample was taken from the following gastrointestinal (GI) sections for brush border membrane enzyme activity analysis: central part of the proximal intestine (PI), mid-intestine (MI, $1 / 2$ the distance between the pyloric caeca and the intestinal constriction), distal intestine (DI, from the constriction to the anus). All digestive organ samples were placed in tubes and immediately frozen in liquid nitrogen and stored at $-80{ }^{\circ} \mathrm{C}$ until enzyme assay. For the histological evaluation, DI samples were taken from four of the six sampled fish per tank, placed in $4 \%$ phosphate-buffered formaldehyde solution for $24 \mathrm{~h}$, and subsequently stored in $70 \%$ ethanol until further processing. For mRNA extraction, DI samples from the four fish selected for histological evaluation were placed in RNA later (Ambion) at $4{ }^{\circ} \mathrm{C}$ for $24 \mathrm{~h}$ and then stored at $-20{ }^{\circ} \mathrm{C}$ until use. 2.4 Chemical analysis

Standard methods (AOAC, 1995) were used for analyzing experimental diets and carcasses samples. Moisture and ash content were determined gravimetrically to constant weight in an oven at $105{ }^{\circ} \mathrm{C}$ and $550{ }^{\circ} \mathrm{C}$, respectively. Crude lipid was determined gravimetrically after extraction with ethyl ether (Extraction System B-811, BUCHI, Switzerland). Crude protein was determined by Kjeldahl method with a FOSS Kjeltec System (2300, Sweden) using boric acid to trap released ammonia. Gross energy was determined by calorimetric bomb (Parr, Moline, IL, USA). Amino acids in feed ingredients and diets (Table 2) were determined by amino acid analyser (Biochrom 30, GE Health care Co. Ltd, Cambridge, UK).

2.5 Brush border membrane enzyme activity

To obtain an adequate crude enzyme extract solution, the samples were thawed and 
homogenized (1:20) in ice-cold Tris (2 mM)-mannitol (50 mM) buffer, $\mathrm{pH} 7.1$, containing phenylmethyl-sulphonyl fluoride (Sigma No. P7626, Sigma Chemical CO., St. Louis, MO) as a serine proteinase inhibitor. Following centrifugation $\left(9000 \times \mathrm{g}, 30 \mathrm{~min}, 4^{\circ} \mathrm{C}\right)$, the supernatants were removed and kept at $4{ }^{\circ} \mathrm{C}$ for analysis.

Maltase activity was measured according to the methods described by Dahlqvist (1970) using maltose as substrate. The data acquisition system was run at $505 \mathrm{~nm}$ with the microplate reader for the generated glucose concentration. The standard curve for the correlation between the concentration of glucose and absorbance at $550 \mathrm{~nm}$ was prepared before analysis and was used subsequently. One unit (U) of maltase activity was defined as the amount of enzyme that degraded $1 \mathrm{mmol}$ maltose (2 mmol glucose generated) per minute. Specific activity was expressed as maltase units/mg protein.

Leucine aminopeptidase (LAP) was measured colorimetrically using the substrate L-leucine $\beta$-naphthylamide hydrochloride as described by Krogdahl et al. (2003). The data acquisition system was run at $580 \mathrm{~nm}$ with the spectrophotometer. The standard curve for the correlation between the concentration of 2-Naphthylamine and absorbance at $580 \mathrm{~nm}$ was prepared before analysis and was used subsequently. One unit (U) of LAP activity was defined as the amount of enzyme that degraded $1 \mathrm{mmol}$ substrate per hour. Specific activity was expressed as LAP units/mg protein.

Alkaline phosphatase activity was determined spectrophotometrically at $520 \mathrm{~nm}$, with alkaline phosphatase (ALP) detection kit (Nanjing Jiancheng Bioengineering Institute, Nanjing, China). The standard curve for the correlation between the concentration of standard phenol substrate and absorbance at $520 \mathrm{~nm}$ was prepared before analysis and was used subsequently. One unit of ALP activity was defined as the amount of enzyme that reacted with the matrix on alkaline condition and produced $1 \mathrm{mg}$ phenol in $30 \mathrm{~min}$. Specific activity was expressed as ALP units/g protein.

In order to standardize the levels of enzyme activities, total protein in homogenate of each sample was measured using a commercial kit (Nanjing Jiancheng Bioengineering Institute, Nanjing, China), based on the method described by Bradford (1976). Following the instruction of the kit, blank tube, standard tube and measuring tube were set and besides the color developing agent, purified water, standard protein solution and homogenized sample solution were added, respectively. Bovine serum albumin provided with the kit was used as standard. And the protein concentration in the sample solution was calculated as follow: Protein concentration $\left(\mathrm{g} \mathrm{L}^{-1}\right)=$ ((O.D. 595 of measuring tube - O.D. 595 of blank tube)/(O.D. 595 of standard tube - O.D. 595 of blank tube)) $\times$ standard protein solution concentration $\left(\mathrm{g} \mathrm{L}^{-1}\right)$

\subsection{Histology}

After fixation in formalin, samples from DI were dehydrated in ethanol, equilibrated in xylene and embedded in paraffin according to standard histological techniques. Sections of approximately $5 \mu \mathrm{m}$ were cut and stained with haematoxylin and eosin (H\&E). Examination was conducted blindly with a light microscope using a continuous scoring scale from 0 to 10 as described by Penn et al. (2011). The following histological characteristics were evaluated: length and fusion of mucosal folds, cellular infiltration and width of the lamina propria and submucosa, enterocyte vacuolization and nucleus position within the enterocytes.

\subsection{Quantitative Real Time PCR (qPCR)}

Total RNA was extracted and purified from DI tissue samples (approximately $50 \mathrm{mg}$ ) of FM, SBM26, SBM40 and SBM54 fed fish (12 samples/group) using RNeasy protect Mini Kit (Qiagen, 
74126) according to manufacturer's instructions. RNA was quantified using NanoDrop ${ }^{\circledR}$ ND-1000 spectrophotometer (NanoDrop ${ }^{\circledR}$ Technologies Inc.) and its quality was checked in an Agilent BioAnalizer (Agilent Technologies, USA). The cDNA synthesis was performed with the QuantiTect Reverse Transcription Kit (Qiagen, 205311) using 1.0 $\mu \mathrm{g}$ of RNA and following the manufacturer indications.

The expression profiles of the genes of interleukin-1 beta (il-1 $\beta$ ), interleukin 8 (il-8), interleukin 17A/F (il-17a/f), interleukin 22 (il-22), tumour necrosis factor alpha (tnf-a) and transforming growth factor beta $(\operatorname{tg} f-\beta)$ were determined using real-time quantitative PCR (qPCR). The expressions of individual gene targets were analysed using the Bio-Rad CFX Connect real time system (Bio-Rad). Primer sequences are listed in Table 3. The constitutively expressed ribosomal protein S4 (RPS4), proved to be stably expressed in turbot (Millán et al., 2011; Robledo et al., 2014), was chosen as the house-keeping gene for sample normalisation. Individual real-time PCR reactions were carried out in $25 \mu \mathrm{l}$ reaction volume using $12.5 \mu \mathrm{l}$ of SYBR Green PCR Master Mix (QuantiTect SYBR Green RT-PCR Kit, Qiagen, 204243), $10.5 \mu 1$ of ultrapure water (Sigma-Aldrich), $0.5 \mu \mathrm{l}$ of each specific primer $(10 \mu \mathrm{M})$ and $1 \mu \mathrm{l}$ of five times diluted cDNA template. The thermal profile for SYBR Green RT-PCR was $95^{\circ} \mathrm{C}$ for $20 \mathrm{~s}$, followed by 40 cycles of $95^{\circ} \mathrm{C}$ for $5 \mathrm{~s}, 58-60^{\circ} \mathrm{C}$ for $30 \mathrm{~s}$, and $72^{\circ} \mathrm{C}$ for $30 \mathrm{~s}$. Each sample was performed in duplicate for accuracy and error estimation including one reverse-transcription-negative control for each gene. Fluorescence readings at the end of each cycle were used to estimate threshold cycle values $(\mathrm{Ct})$. Values were normalized to RPS4 and fold change in transcript level determined with the relative quantitative method $\left(2^{-\Delta \Delta C T}\right)$ (Livak and Schmittgen, 2001).

2.8 Calculations

Weight gain, WG $(\%)=100 \times(($ final body weight - initial body weight $) /$ initial body weight $)$

Feed intake, FI $(\% /$ day $)=100 \times$ total amount of the feed consumed $/(($ initial body weight + final body weight) /2) / days

Feed efficiency ratio, FER = weight gained / total amount of the feed consumed

Protein efficiency ratio $=$ body weight gain $/$ protein intake

Gross protein efficiency, GPE $=100 \times((\%$ final body protein $\times$ final body weight $)-(\%$ initial body protein $\times$ initial body weight)) / total protein intake

The condition factor and organosomatic index were calculated as follows:

Condition factor, $\mathrm{CF}=100 \times$ fish weight $/$ (body length $)^{3}$

Intestinal somatic index, ISI $(\%)=100 \times($ intestinal weight $/$ body weight $)$

Hepatosomatic index, HSI $(\%)=100 \times$ (hepatopancreas weight $/$ body weight $)$

\subsection{Statistical analysis}

Effects of the inclusion levels of soybean meal were evaluated using regression analysis. The results were fit to polynomial models of first, second, and third degrees. The model considered to fit the results best on the basis of visual examination and the observed $\mathrm{R}^{2}$ is reported.

\section{Results}

3.1 Growth performance and nutrient utilization

During the feeding trial no mortality was recorded. The effects of the experimental diets on turbot growth performance and nutrient utilization are shown in Table 4 and Fig. 1. The regression analysis showed a significant inverse relationship between growth and SBM level following a first-degree relationship. The FI decreased significantly with the increasing SBM level, fitting a 
second-degree relationship, and FER, PER and GPE showed the same picture. Increasing level of SBM reduced FER, PER and GPE following a second-degree relationship; i.e., the effect became more pronounced at higher levels.

3.2 Whole body compositions and biometric parameters

Whole body compositions and biometric parameters are shown in Table 4 and Fig. 2. The protein and lipid compositions of fish decreased with the increasing of SBM inclusion following a second-degree regression best. The relationship was opposite for moisture and ash compositions. The regression analysis showed that condition factor was significantly increased whereas the relationship of ISI was opposite, although for both, the relationship fit a first degree. The HSI decreased with the increasing of SBM inclusion, fitting a second-degree regression best.

\subsection{Brush border membrane enzyme activities}

Enzyme activities are presented as specific activity and the data are shown in Table 5 and Fig. 3. In PI, no significant dietary SBM effect was observed. In MI, the SBM inclusion level significantly decreased the LAP and ALP specific activities following a first-degree relationship. In DI, increasing dietary SBM levels significantly decreased the specific activities of all the three tested brush border membrane enzymes (Maltase, LAP and ALP) markedly. The relationship followed a second-degree function, with a more pronounced effect at higher levels.

\subsection{Morphology of the distal intestine}

The SBM inclusion level affected all the characteristics assessed and showed alterations typical for mucosal inflammation (Table 6, Fig. 4 and Fig. 5). The severity increased with increasing level of SBM inclusion. SBM inclusion decreased height and increased fusion of the mucosal folds, increased width and cellular (leucocyte) infiltration of the lamina propria and submucosa, reduced numbers of supra-nuclear absorptive vacuoles in enterocytes and displaced nuclei toward the apexes of the cells. Except for the mucosal fold height fitting best a first-degree relationship, all the other characteristics followed a second-degree relationship best, with increasing effect with increasing SBM level.

\subsection{Gene expression}

As can be seen from the Table 6 and Fig. 6, all inflammation indicators showed gradual and accelerating increases with increasing SBM inclusion in the diet, fitting a second-degree relationship. Moreover, even at the $26 \%$ dose elevation was apparent for most of these variables indicating that even lower inclusion levels might affect the immune apparatus of the gut.

\section{Discussion}

The significant decrease in feed intake and WG observed with the increasing SBM inclusion level in the present study is in agreement with results of numerous studies conducted on carnivorous fish species, as reviewed by Bowyer et al. (2013). Also previous studies with turbot, have revealed negative effects of plant protein sources (PP) on feed intake (Fournier et al., 2004) and growth (Fournier et al., 2004; Bonaldo et al., 2011; Yun et al., 2011; Nagel et al., 2014; Bonaldo et al., 2015). The dose-dependently decreased feed intake observed in the present study was most likely the major cause of this SBM effect. Several researchers have suggested that poor palatability of diets containing SBM can be responsible for the limited consumption and thus reduced growth observed in many species (Bonaldo et al., 2011), and this could be the cause of the reduced feed intake in fish fed SBM diets in the present study as well. According to Bureau et al. (1998), the low palatability of this ingredient may be due to the bitter taste of saponins. 
In the current study, the results showing decrease of FER with increasing dietary SBM and which coincided with reduced protein utilization (PER and GPE) are in agreement with earlier studies evaluating PP inclusion in turbot diets (Regost et al., 1999; Day and González, 2000; Bonaldo et al., 2011; Bonaldo et al., 2015). The observation that fish with increasing level of SBM in their diet show gradually decreasing nutrient utilization is in accordance with nutritional principles. With decreasing growth rate the maintenance requirement, which is constant and gives no product, represents a greater share of total nutrient requirement, and the result is decreased gain for each unit of input.

Our finding that SBM caused dose-dependent decreases in crude protein and crude lipid compositions in whole body of turbot, with significantly increasing of moisture and ash compositions are in accordance with those of Regost et al. (1999) and Fournier et al. (2004), but deviates from those of Burel et al. (2000) and Bonaldo et al. (2011) in which whole body compositions remained unchanged irrespective of dietary PP treatment. In the present study, CF decreased with increasing SBM inclusion and this phenomenon was also observed by Bonaldo et al. (2011), who suggested the lower CF could be due to a reduced development of muscle in fish, leading to a lower thickness of fillets.

The significantly decreased of the relative weight of liver by SBM inclusion was most likely due to lower feed intake. However, the higher ISI might be a result of a compensatory response to challenges to the digestive processes linked to fibers and possibly other ANFs in SBM. Fiber-rich diets have been proved to induce growth of intestinal tissues in Atlantic salmon (Refstie et al. 2006a) and cod (Refstie et al. 2006b), possibly due to a need for a larger absorptive surface area when the volume of the chyme increases due to swelling of the fiber.

The current study clearly demonstrated that SBM inclusion caused a dose dependent increase in level of the observed indicators of inflammation in DI of the turbot. The observations were similar to those described for SBMIE in other carnivorous fish species (van den Ingh et al., 1991; Rumsey et al., 1994; Baeverfjord and Krogdahl, 1996; Bakke-McKellp et al., 2000; Krogdahl et al., 2003; Yamamoto et al., 2008; Urán et al., 2008; Hedrera et al., 2013). As far as we know, the present study is the first to report SBMIE in turbot. In Atlantic salmon, it has been reported that inclusion as low as 5-10\% SBM in the diet could produce detrimental inflammatory effects at the intestinal level (Krogdahl et al., 2003; Urán et al., 2009), a level much lower than what is needed for induction of similar responses in turbot. This difference indicates that turbot have higher tolerance for SBM than Atlantic salmon. The decreases in DI brush border membrane enzymes (Maltase, LAP and ALP) activities and the marked up-regulation of inflammatory related genes are signs of dysfunction caused by the SBMIE. However, since the intestinal sections were not weighed, the results of brush border membrane enzymes may also be an effect of increased protein level in the brush border without alteration in enzyme activity, or a combination of changes in enzyme and protein content. This possible reason could not be excluded. The recent work of Krogdahl et al. (2015) demonstrates that soya saponins alone is sufficient to induce the condition called SBMIE. However, the study also suggests that other antinutrients present in soybean meal and other legumes may enhance the saponins effects in line with indications from other studies (Bureau et al., 1998; Knudsen et al., 2008). Whether saponins alone or combined with other ANFs would induce SBMIE in turbot still needs to be clarified.

As indicated in the previous studies, and demonstrated in the present, inflammatory cell infiltration in lamina propria and submucosa correlates with pro-inflammatory cytokine 
production. In the current study, the up-regulation of four of the observed pro-inflammatory genes (il-1 $\beta$, il-8, tnf- $\alpha$ and il-17a/f) in SBM-fed fish are in accordance with the observations in Atlantic salmon (Marjara et al., 2012), common carp (Urán et al., 2008) and zebra fish (Hedrera et al., 2013). The increasing number of lymphocytes and other immune cells in the epithelium (IELs), lamina propria and submucosa observed in the current study are supposedly important sources of the pro-inflammatory cytokines found differentially regulated during the progression of inflammation. Among the genes related to recruitment and/or differentiation of inflammatory, the cytokine IL-17 has been suggested as a sensitive molecular marker for SBMIE in Atlantic salmon (Marjara et al., 2012). Our study strengthened this conclusion, since its transcript level displayed a $>100$-fold increase in SBM-60 fed fish. In humans and animal models with inflammatory bowel diseases, IL-17 has been suggested to play a decisive role in the production of cytokines that facilitate the recruitment of macrophages and neutrophils into inflamed intestine, as well as to coordinate intestinal inflammation by inducing the synthesis of other inflammatory molecules, such as IL-22 and TNF- $\alpha$ (Weaver et al., 2007; Andoh et al., 2002). The up-regulatory effect of SBM on the mRNA expression of tgf- $\beta$ is in line with the results observed in Atlantic salmon by Marjara et al. (2012). Lilleeng et al. (2009), on the other hand showed the opposite effects. Our results are also in line with observations in common carp (Urán et al., 2008).

In the present work, dietary SBM levels were set based on our primary work and previous research on SBM in turbot. Well-development experiment technologies for SBMIE in fish were employed and brought comprehensive results for SBMIE in turbot. These results confirm the hypothesis that high inclusion level of SBM (in the range of 26-54\%) could cause the similar inflammatory changes in turbot as seen in several other fish species. The present work directly suggested that caution must be taken when formulating turbot diets based on ingredients that may contain saponins of other antinutrients. Moreover, turbot may be employed as a model for the study of the causes and mechanism underlying diet induced inflammation in the intestine of fish and for the alleviating technology development. 
325

326

327

328

329

330

\section{Acknowledgments}

This study was jointly supported by the National Science Foundation for Distinguished Young Scholars of China (Grant No. 3150130398), Shandong Provincial Natural Science Foundation of China (Grant No. 2014ZRE27587) and Independent Innovation Foundation of Shandong University (Grant No. 1070501314005). All authors read and approved the final manuscript. 


\section{Reference}

Andoh, A., Hata, K., Araki, Y., Fujiyama, Y., Bamba, T., 2002. Interleukin (IL)-4 and IL-17 synergistically stimulate IL-6 secretion in human colonic myofibroblasts. Int. J. Mol. Med. $10,631-634$.

Association of Official Analytical Chemist (AOAC), 1995. Official Methods of Analysis of AOAC International, 16th edn. AOAC Inc., Arlington, VA, USA.

Baeverfjord, G. Krogdahl, Å. 1996. Development and regression of soybean meal induced enteritis in Atlantic salmon, Salmo salar L., distal intestine: a comparison with the intestines of fasted fish. J. Fish Dis. 19, 375-387.

Bakke-McKellep, A.M., Frøystad, M.K., Lilleeng, E., Dapra, F., Refstie, S., Krogdahl, Å., Landsverk, T., 2007. Response to soy: T-cell-like reactivity in the intestine of Atlantic salmon, Salmo salar L. J. Fish Dis. 30, 13-25.

Bakke-McKellep, A.M., Press, C.M., Baeverfjord, G., Krogdahl, Å., Landsverk, T., 2000. Changes in immune and enzyme histochemical phenotypes of cells in the intestinal mucosa of Atlantic salmon, Salmo salar L., with soybean meal-induced enteritis. J. Fish Dis. 23, 115-127.

Bonaldo, A., Di Marco, P., Petochi, T., Marino, G., Parma, L., Fontanillas, R., Koppe, W., Mongile, F., Finoia, M.G., Gatta, P.P., 2015. Feeding turbot juveniles Psetta maxima L. with increasing dietary plant protein levels affects growth performance and fish welfare. Aquacult. Nutr. 21, 401-413.

Bonaldo, A., Parma, L., Mandrioli, L., Sirri, R., Fontanillas, R., Badiani, A., Gatta, P.P., 2011. Increasing dietary plant proteins affects growth performance and ammonia excretion but not digestibility and gut histology in turbot (Psetta maxima) juveniles. Aquaculture 318, 101108.

Bowyer, J.N., Qin, J.G., Stone, D.A., 2013. Protein, lipid and energy requirements of cultured marine fish in cold, temperate and warm water. Rev. Aquacult. 5, 10-32.

Bradford, M.M., 1976. A rapid and sensitive method for the quantitation of microgram quantities of protein utilizing the principle of protein-dye binding. Anal. Biochem. 72, 248-254.

Bureau, D.P., Harris, A.M., Young Cho, C., 1998. The effects of purified alcohol extracts from soy products on feed intake and growth of chinook salmon (Oncorhynchus tshawytscha) and rainbow trout (Oncorhynchus mykiss). Aquaculture 161, 27-43.

Burel, C., Boujard, T., Kaushik, S.J., Boeuf, G., Van Der Geyten, S., Mol, K.A., Kühn, E.R., Quinsac, A., Krouti, M., Ribaillier, D., 2000. Potential of plant-protein sources as fish meal substitutes in diets for turbot (Psetta maxima): growth, nutrient, utilisation and thyroid status. Aquaculture 188, 363-382.

Costa, M.M., Pereiro, P., Wang, T., Secombes, C.J., Figueras, A., Novoa, B., 2012. Characterization and gene expression analysis of the two main Th17 cytokines (IL-17A/F and IL-22) in turbot, Scophthalmus maximus. Dev. Comp. Immunol. 38, 505-516.

Costa, M.M., Saraceni, P.R., Forn-Cuní, G., Dios, S., Romero, A., Figueras, A., Novoa, B., 2013. IL-22 is a key player in the regulation of inflammation in fish and involves innate immune cells and PI3K signaling. Dev. Comp. Immunol. 41, 746-755.

Dahlqvist A., 1970. Assay of intestinal disaccharidases. Enzymol. Biol. Clin. 11, 52-66.

Day, O.J., González, H.G.P., 2000. Soybean protein concentrate as a protein source for turbot Scophthalmus maximus L. Aquacult. Nutr. 6, 221-228.

De Santis, C., Bartie, K.L., Olsen, R.E., Taggart, J.B., Tocher, D.R., 2015. Nutrigenomic profiling 
of transcriptional processes affected in liver and distal intestine in response to a soybean meal-induced nutritional stress in Atlantic salmon (Salmo salar). Comp. Biochem. Physiol. D: Genomics Proteomics, 15, 1-11.

FAO FishStatJ, 2013. Universal Software for Fishery Statistical Time Series. FAO, Statistics and Information Service, FAO Fisheries Department, Fishery Information, Data and Statistics Unit, Rome, Italy. http://www.fao.org/fishery/statistics/software/fishstatj/en (accessed 3 May 2013).

Fournier, V., Huelvan, C., Desbruyeres, E., 2004. Incorporation of a mixture of plant feedstuffs as substitute for fish meal in diets of juvenile turbot (Psetta maxima). Aquaculture 236, 451465 .

Grammes, F., Reveco, F.E., Romarheim, O.H., Landsverk, T., Mydland, L.T., Øverland, M., 2013. Candida utilis and Chlorella vulgaris counteract intestinal inflammation in Atlantic salmon (Salmo salar L.). Plos One 8, e83213.

Han, M., Ding, F.H., Meng, Z., Lei, J., 2014. The effect of vaccinating turbot broodstocks on the maternal immunity transfer to offspring immunity. Fish Shellfish Immun. 39, 118-124.

Hardy, R.W., Kissil G.W.M., 1997. Trends in aquaculture feeding. Feed Mix 5, 31-34.

Hedrera, M.I., Galdames, J.A., Jimenez-Reyes, M.F., Reyes, A.E., Avendaño-Herrera, R., Romero, J., Feijóo, C.G., 2013. Soybean meal induces intestinal inflammation in zebrafish larvae. PloS one 8, e69983.

Kaushik, S.J., 1998. Whole body amino acid composition of European seabass (Dicentrarchus labrax), gilthead seabream (Sparus aurata) and turbot (Psetta maxima) with an estimation of their IAA requirement profiles. Aquat. Living Resour. 11, 355-358.

Knudsen, D., Jutfelt, F., Sundh, H., Sundell, K., Koppe, W., Frøkiær, H., 2008. Dietary soya saponins increase gut permeability and play a key role in the onset of soyabean-induced enteritis in Atlantic salmon (Salmo salar L.). Brit. J. Nutr. 100, 120-129.

Krogdahl, A.., Bakke-McKellep, A.M., Baeverfjord, G., 2003. Effects of graded levels of standard soybean meal on intestinal structure, mucosal enzyme activities, and pancreatic response in Atlantic salmon (Salmo salar L.). Aquacul. Nutr. 9, 361-371.

Krogdahl, Å., Gajardo, K., Kortner, T.M., Penn, M., Gu, M., Berge G.M., Bakke, A.M., 2015. Soya saponins induce enteritis in Atlantic salmon (Salmo salar L.). J. Agr. Food Chem. 63.

Lilleeng, E., Penn, M.H., Haugland, Ø., Xu, C., Bakke, A.M., Krogdahl, Å., Landsverk, T., Frøystad-Saugen, M.K., 2009. Decreased expression of TGF- $\beta$, GILT and T-cell markers in the early stages of soybean enteropathy in Atlantic salmon (Salmo salar L.). Fish Shellfish Immunol. 27, 65-72.

Livak, K.J., Schmittgen, T.D., 2001. Analysis of relative gene expression data using real-time quantitative pcr and the 2 method. Methods, 25(4), 402-408.

Marjara, I.S., Chikwati, E.M., Valen, E.C., Åshild, K., Anne Marie, B., 2012. Transcriptional regulation of il-17a and other inflammatory markers during the development of soybean meal-induced enteropathy in the distal intestine of Atlantic salmon (salmo salar L.). Cytokine 60, 186-196.

Merrifield, D., Olsen, R.E., Myklebust, R., Ringø, E., 2011. Dietary effect of soybean (Glycine max) products on gut histology and microbiota of Fish, in: Hany El-Shemy (Eds.), Agricultural and Biological Sciences: Soybean and Nutrition. INTECH Open Access Publisher. 
Millán, A., Gómez-Tato, A., Pardo, B. G., Fernández, C., Bouza, C., Vera, M., Alvarez-Dios, J.A., Cabaleiro, S., Lamas, J., Martínez, P., 2011. Gene expression profiles of the spleen, liver, and head kidney in turbot (Scophthalmus maximus) along the infection process with Aeromonas salmonicida using an immune-enriched oligo-microarray. Mar. Biotechnol. 13, 1099-1114.

Nagel, F., von Danwitz, A., Schlachter, M., Kroeckel, S., Wagner, C., Schulz, C., 2014. Blue mussel meal as feed attractant in rapeseed protein-based diets for turbot (Psetta maxima L.). Aquac. Res. 45, 1964-1978.

Ordás, M.C., Costa, M.M., Roca, F.J., Lopez-Castejon, G., Mulero, V., Meseguer, J., Figuerasa, A. Novoa, B., 2007. Turbot TNF $\alpha$ gene: molecular characterization and biological activity of the recombinant protein. Mol. Immunol. 44, 389-400.

Penn, M.H., Bendiksen, E.Å., Campbell, P., Krogdahl, Å., 2011. High level of dietary pea protein concentrate induces enteropathy in Atlantic salmon (Salmo salar L.). Aquaculture 310, $267-$ 273.

Peres, H., Oliva-Teles, A., 2008. Lysine requirement and efficiency of lysine utilization in turbot (Scophthalmus maximus) juveniles. Aquaculture 275, 283-290.

Refstie, S., Bakke-McKellep, A.M., Penn, M.H., Sundby, A., Shearer, K.D., Krogdahl, Å., 2006 a. Capacity for digestive hydrolysis and amino acid absorption in Atlantic salmon (Salmo salar) fed diets with soybean meal or inulin with or without addition of antibiotics. Aquaculture 261, 392-406.

Refstie, S., Førde-Skjærvik, O., Rosenlund, G., Rørvik, K.J., 2006b. Feed intake, growth, and utilisation of macronutrients and amino acids by 1-and 2-year old Atlantic cod (Gadus morhua) fed standard or bioprocessed soybean meal. Aquaculture 255, 279-291.

Regost, C., Arzel, J., Kaushik, S.J., 1999. Partial or total replacement of fish meal by corn gluten meal in diet for turbot (Psetta maxima). Aquaculture 180, 99-117.

Robledo, D., Hernández-Urcera, J., Cal, R. M., Pardo, B. G., Sánchez, L., Martínez, P., Viñas, A., 2014. Analysis of qPCR reference gene stability determination methods and a practical approach for efficiency calculation on a turbot (Scophthalmus maximus) gonad dataset. BMC genomics 15,1 .

Robledo, D., Hernández-Urcera, J., Cal, R.M., Pardo, B.G., Sánchez, L., Martínez, P., Viñas, A., 2014. Analysis of qPCR reference gene stability determination methods and a practical approach for efficiency calculation on a turbot (Scophthalmus maximus) gonad dataset. BMC Genomics 15, 1.

Rumsey, G.L., Siwicki, A.K., Anderson, D.P., Bowser, P.R., 1994. Effect of soybean protein on serological response, non-specific defense mechanisms, growth, and protein utilization in rainbow trout. Vet. Immunol. Immunop. 41, 323-339.

Sahlmann, C., Sutherland, B.J., Kortner, T.M., Koop, B.F., Krogdahl, Å., Bakke, A.M., 2013. Early response of gene expression in the distal intestine of Atlantic salmon (Salmo salar L.) during the development of soybean meal induced enteritis. Fish shellfish Immunol. 34, 599609.

Skugor, S., GRISDAlE-HELlAND, B., Refstie, S., Afanasyev, S., Vielma, J., Krasnov, A., 2011. Gene expression responses to restricted feeding and extracted soybean meal in Atlantic salmon (Salmo salar L.). Aquacult. Nutr. 17, 505-517.

Storebakken, T., Refstie S., Ruyter B., 2000. Soy products as fat and protein sources in fish feeds for intensive aquaculture, in: Drackley, J.K. (Eds.), Soy in Animal Nutrition. Savoy: Fed 
Animal Science Society, II, USA, pp. 127-170.

Urán, P.A., Gonçalves, A., Taverne-Thiele, J.J., Schrama, J.W., Verreth, J.A.J., Rombout, J.H.W.M., 2008. Soybean meal-induced enteritis in common carp (Cyprinus carpio L.) and the gene expression of inflammatory mediators in intestinal leukocytes. Fish Shellfish Immunol. 25, 751-760.

Urán, P.A., Schrama, J.W., Rombout, J.H.W.M., Taverne-Thiele, J.J., Obach, A., Koppe, W., Verreth, J.A.J., 2009. Time-related changes of the intestinal morphology of Atlantic salmon, Salmo salar L., at two different soybean meal inclusion levels. J. Fish Dis. 32, 733-744.

van den Ingh, T.S.G.A.M., Krogdahl, Å., Olli, J.J., Hendriks, H.G.C.J.M., Koninkx, J.G.J.F., 1991. Effects of soybean-containing diets on the proximal and distal intestine in Atlantic salmon (Salmo salar): a morphological study. Aquaculture 94, 297-305.

Weaver, C.T., Hatton, R.D., Mangan, P.R, Harrington, L.E., 2007. IL-17 family cytokines and the expanding diversity of effector T cell lineages. Annu. Rev. Immunol. 25, 821-852.

Yamamoto, T., Goto, T., Kine, Y., Endo, Y., Kitaoka, Y., Sugita, T., Furuita, H., Iwashita, Y., Suzuki, N., 2008. Effect of an alcohol extract from a defatted soybean meal supplemented with a casein-based semi-purified diet on the biliary bile status and intestinal conditions in rainbow trout Oncorhynchus mykiss (Walbaum). Aquac. Res. 39, 986-994.

Yun, B., Ai, Q., Mai, K., Xu, W., Qi, G., Luo, Y., 2012. Synergistic effects of dietary cholesterol and taurine on growth performance and cholesterol metabolism in juvenile turbot (Scophthalmus maximus L.) fed high plant protein diets. Aquaculture 324, 85-91.

Yun, B., Mai, K., Zhang, W., Xu, W., 2011. Effects of dietary cholesterol on growth performance, feed intake and cholesterol metabolism in juvenile turbot (Scophthalmus maximus L.) fed high plant protein diets. Aquaculture 319, 105-110. 


\section{Figure legends}

Fig. 1. Illustration of relationships between level of dietary soybean meal supplementation (X-axis) and (A) weight gain (\%), (B) feed intake (\%/day), (C) feed efficiency ratio, (D) protein efficiency ratio, (E) gross protein efficiency. The curves illustrate the regression that fits the results best for fish fed the experimental diets according to the regressions shown in Tables 4. Data are expressed as means $\pm \mathrm{SD}(\mathrm{n}=3)$.

Fig. 2. Illustration of relationships between level of dietary soybean meal supplementation (X-axis) and (A) moisture content (\%), (B) protein content (\%), (C) lipid content (\%), (D) ash content (\%) (E) condition factor, $(F)$ intestinal somatic index and $(\mathrm{G})$ hepatosomatic index. The curves illustrate the regression that fits the results best for fish fed the experimental diets according to the regressions shown in Tables 4 . Data are expressed as means $\pm \operatorname{SD}(n=3)$.

Fig. 3. Illustration of relationships between level of dietary soybean meal supplementation (X-axis) and (A) maltase activity in proximal intestine (PI, U/mg protein), (B) maltase activity in mid-intestine (MI), (C) maltase activity in distal intestine (DI), (D) leucine aminopeptidase in PI (U/mg protein), (E) leucine aminopeptidase in MI, (F) leucine aminopeptidase in DI, (G) alkaline phosphatase in PI (U/g protein), (H) leucine aminopeptidase in MI and (I) leucine aminopeptidase in DI. The curves illustrate the regression that fits the results best for fish fed the experimental diets according to the regressions shown in Table 5. Data are expressed as means $\pm \mathrm{SD}(\mathrm{n}=3)$.

Fig. 4. Illustration of relationships between level of dietary soybean meal supplementation (X-axis) and (A) mucosal folds height (score), (B) mucosal folds fusion, (C) lamina propria width, (D) lamina propria cellular infiltration, (E) submucosa width, (F) submucosa cellular infiltration, (G) enterocytes vacuolization, $(\mathrm{H})$ enterocytes nucleus position. The curves illustrate the regression that fits the results best for fish fed the experimental diets according to the regressions shown in Table 6. Data are expressed as means $\pm \operatorname{SD}(n=3)$.

Fig. 5. Representative histomorphological images from hematoxylin and eosin-stained sections of the distal intestine of turbot depicting the dose-dependent increase in the severity of the inflammatory changes with increasing soybean meal supplementation in turbot fed the FM (a-d), SBM26 (e-h), SBM40 (i-1) and SBM54 (m-p) diets. (a, e, i, m) Representative images of decreased height and increased fusion of the mucosal folds with increasing soybean meal level (bar $=500 \mu \mathrm{m})$. (b, f, j, n) Representative images of increased width and cellular (leucocyte) infiltration (arrows) of the lamina propria with increasing soybean meal level (bar $=50 \mu \mathrm{m})$. (c, $\mathrm{g}$, $\mathrm{k}, \mathrm{o})$ Representative images of increased width and cellular (leucocyte) infiltration (arrows) of the submucosa with increasing soybean meal level $(\mathrm{bar}=50 \mu \mathrm{m}) .(\mathrm{d}, \mathrm{h}, \mathrm{l}, \mathrm{p})$ Representative images of reduced numbers of supranuclear absorptive vacuoles in enterocytes, displaced nuclei toward the apexes of the cells with increasing soybean meal level (bar $=20 \mu \mathrm{m}$ ). Data are expressed as means $\pm \mathrm{SD}(\mathrm{n}=12)$. lp: lamina propria; $\mathrm{v}$ : supranuclear absorptive vacuole.

Fig. 6. Illustration of relationships between level of dietary soybean meal supplementation (X-axis) and the relative expression of (A) il-1 $\beta$, (B) il-8, (C) tnf- $\alpha$, (D) il-17a/f, (E) il-22 and (F) tgf- $\beta$. The curves illustrate the regression that fits the results best for fish fed the experimental diets 
530 according to the regressions shown in Tables 6. Abbreviation: il-1 $\beta$, interleukin-1 beta; il-8, 531 interleukin 8 ; il-17a/f, interleukin 17A/F; il-22, interleukin 22; tnf-a, tumour necrosis factor alpha; $532 \operatorname{tg}-\beta$, transforming growth factor beta. Data are expressed as means $\pm \mathrm{SD}(\mathrm{n}=4)$. 
Fig.1
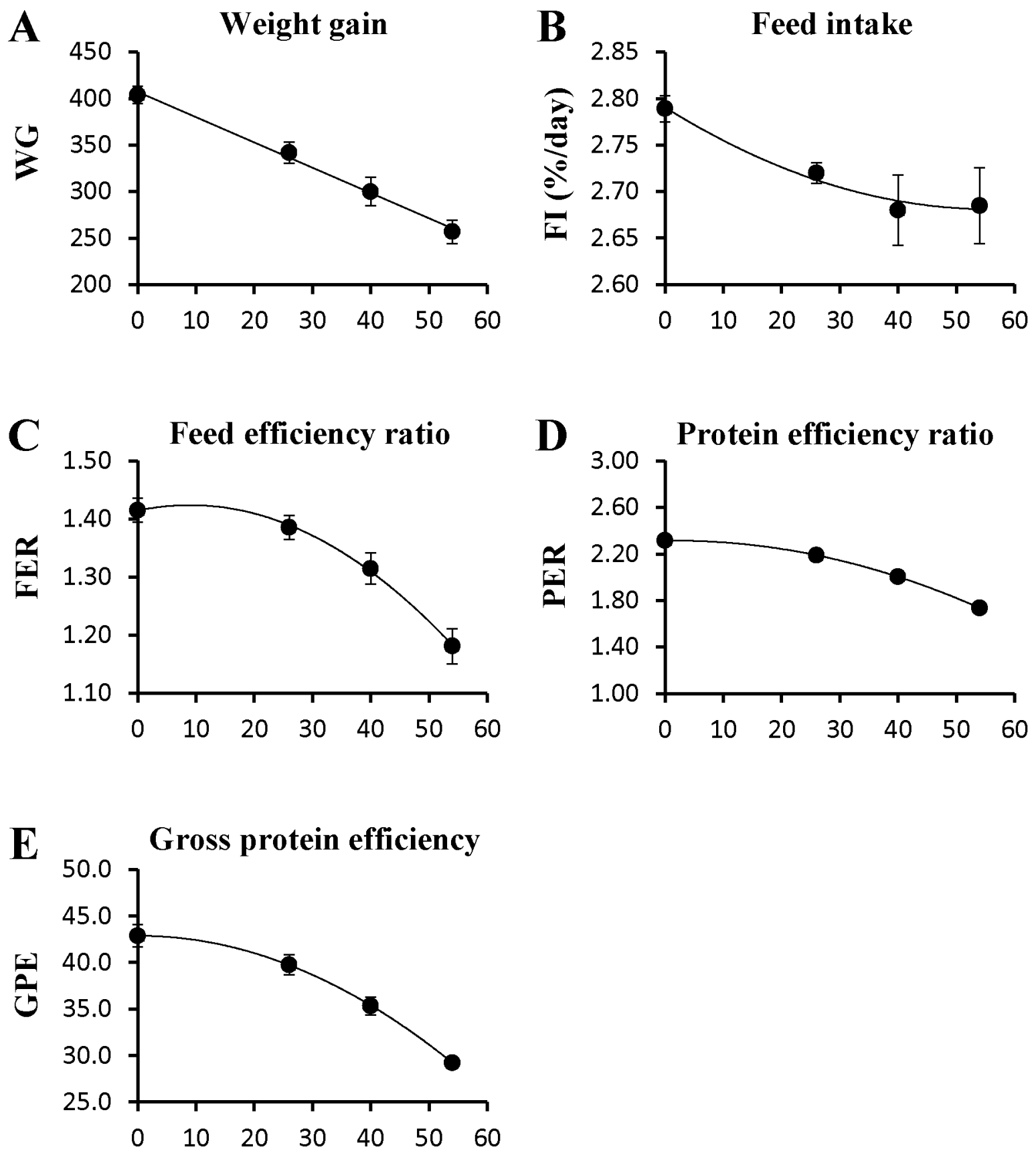
Fig. 2
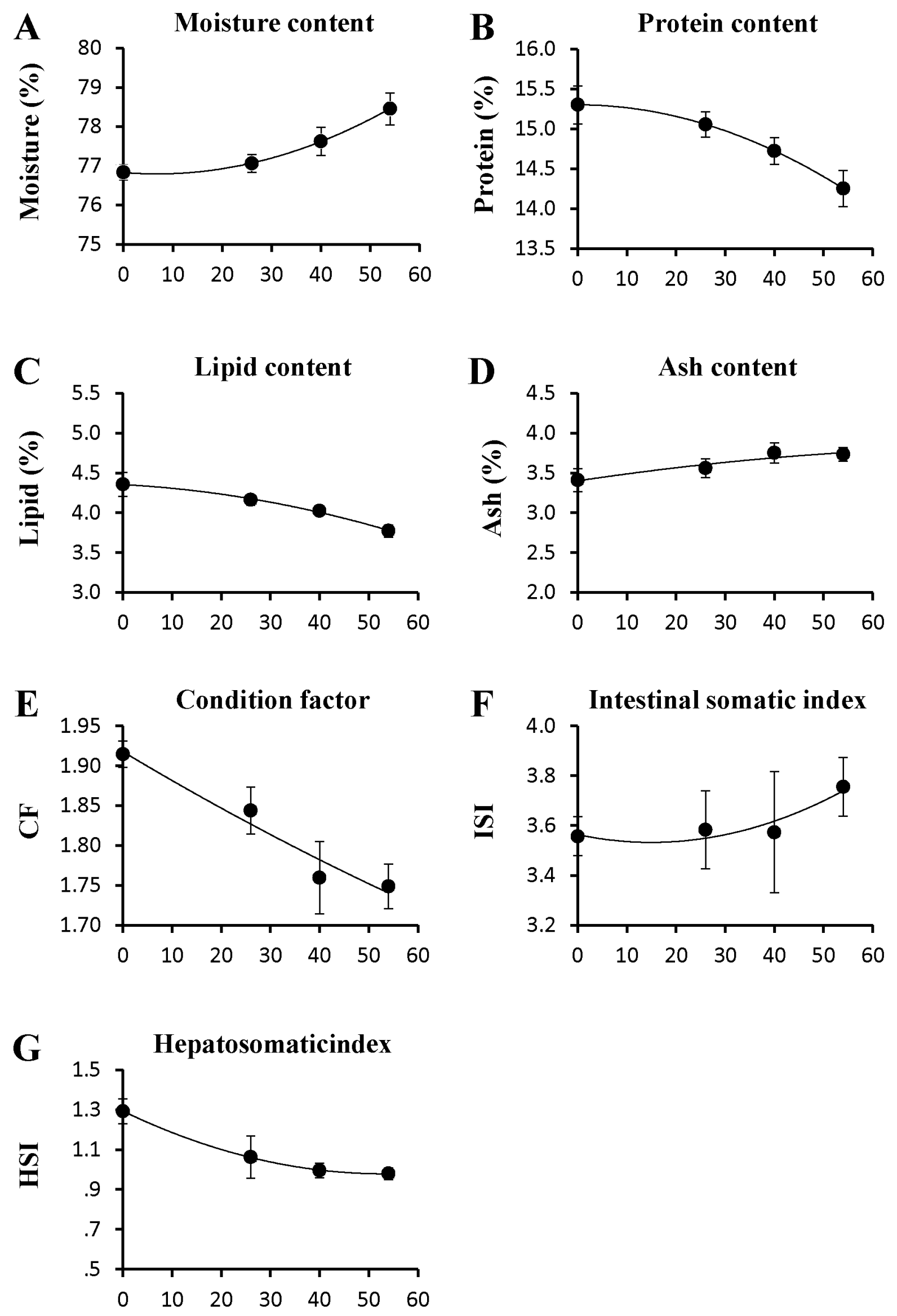
Fig. 3
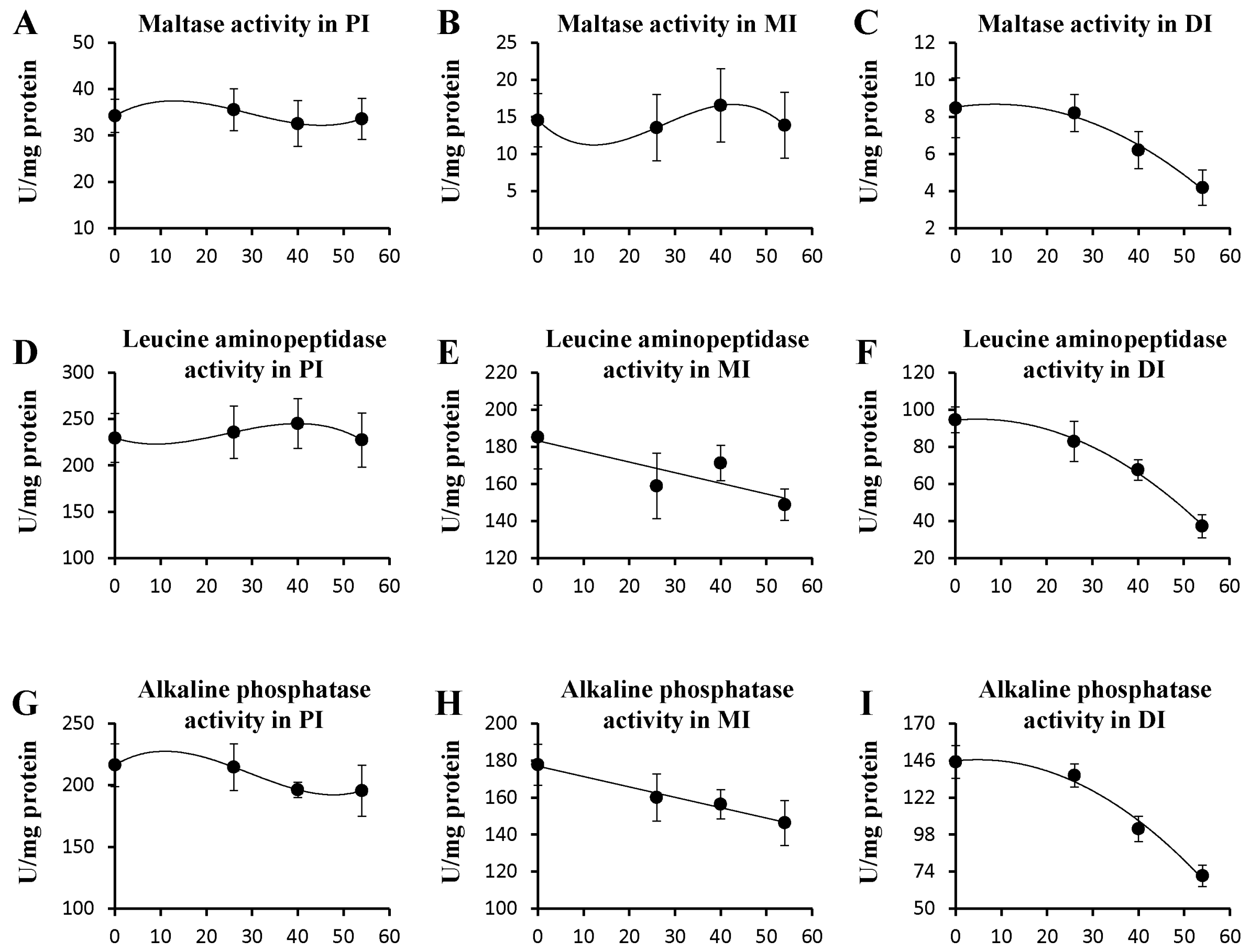
Fig. 4
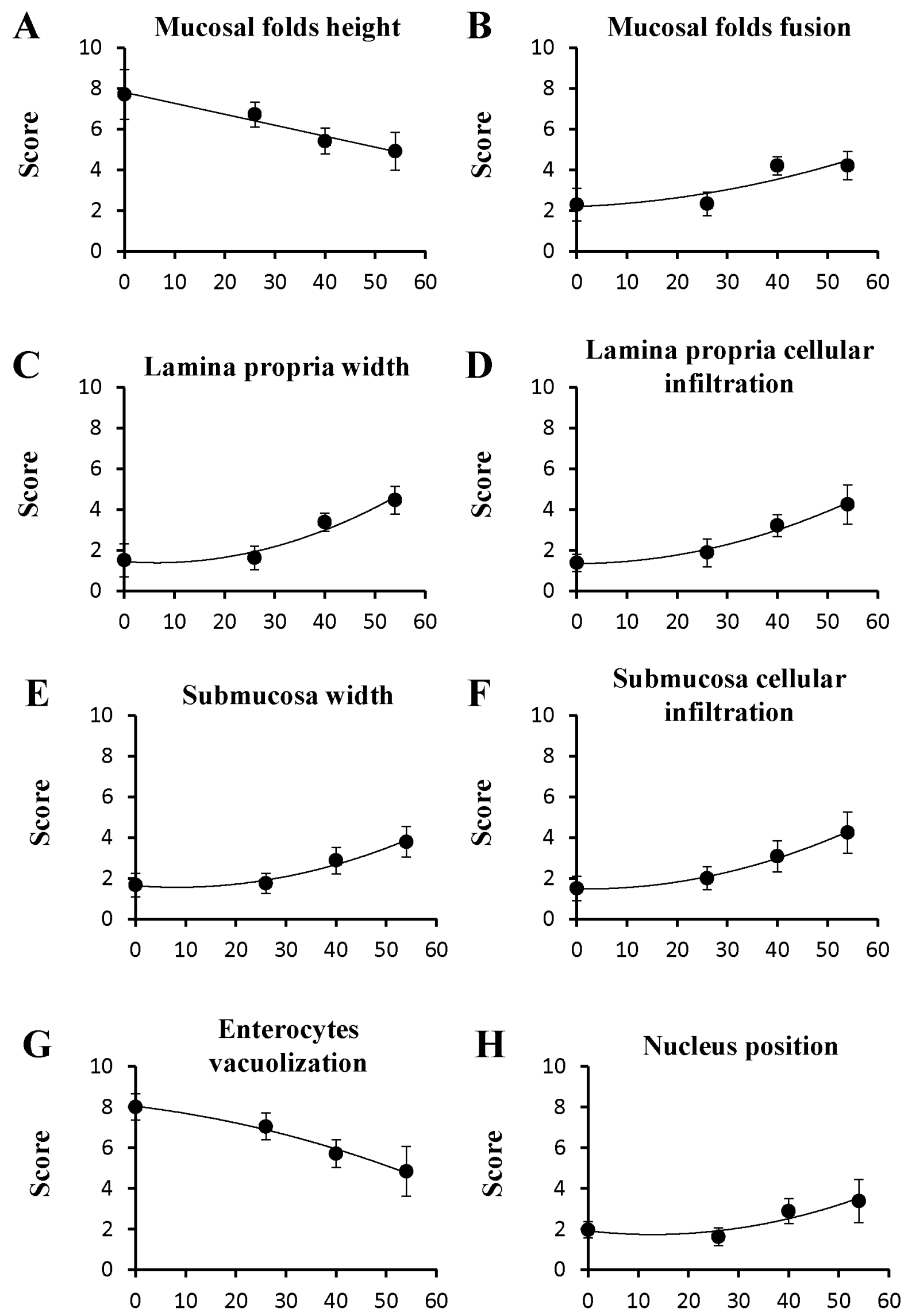
Figure 5
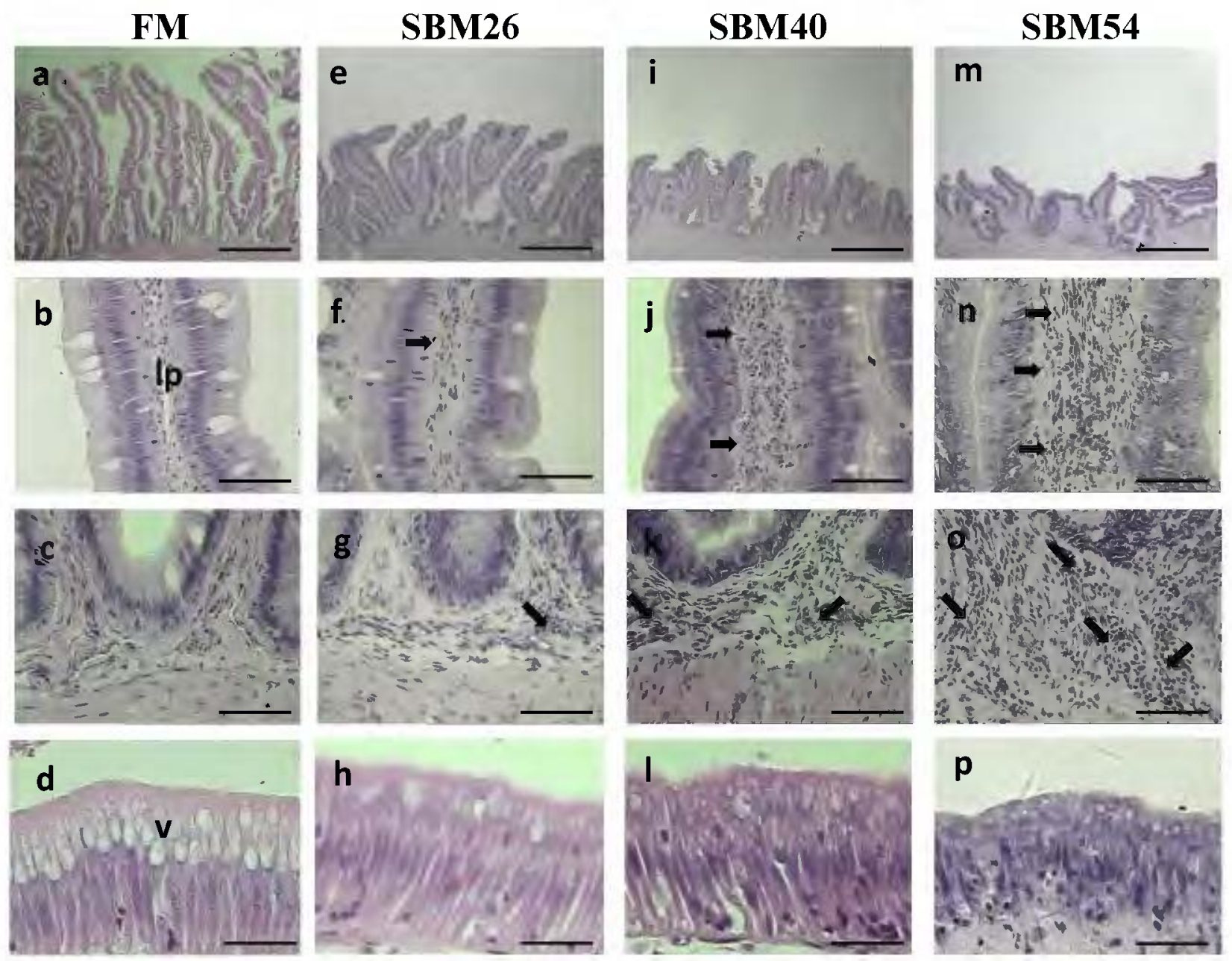
Fig. 6
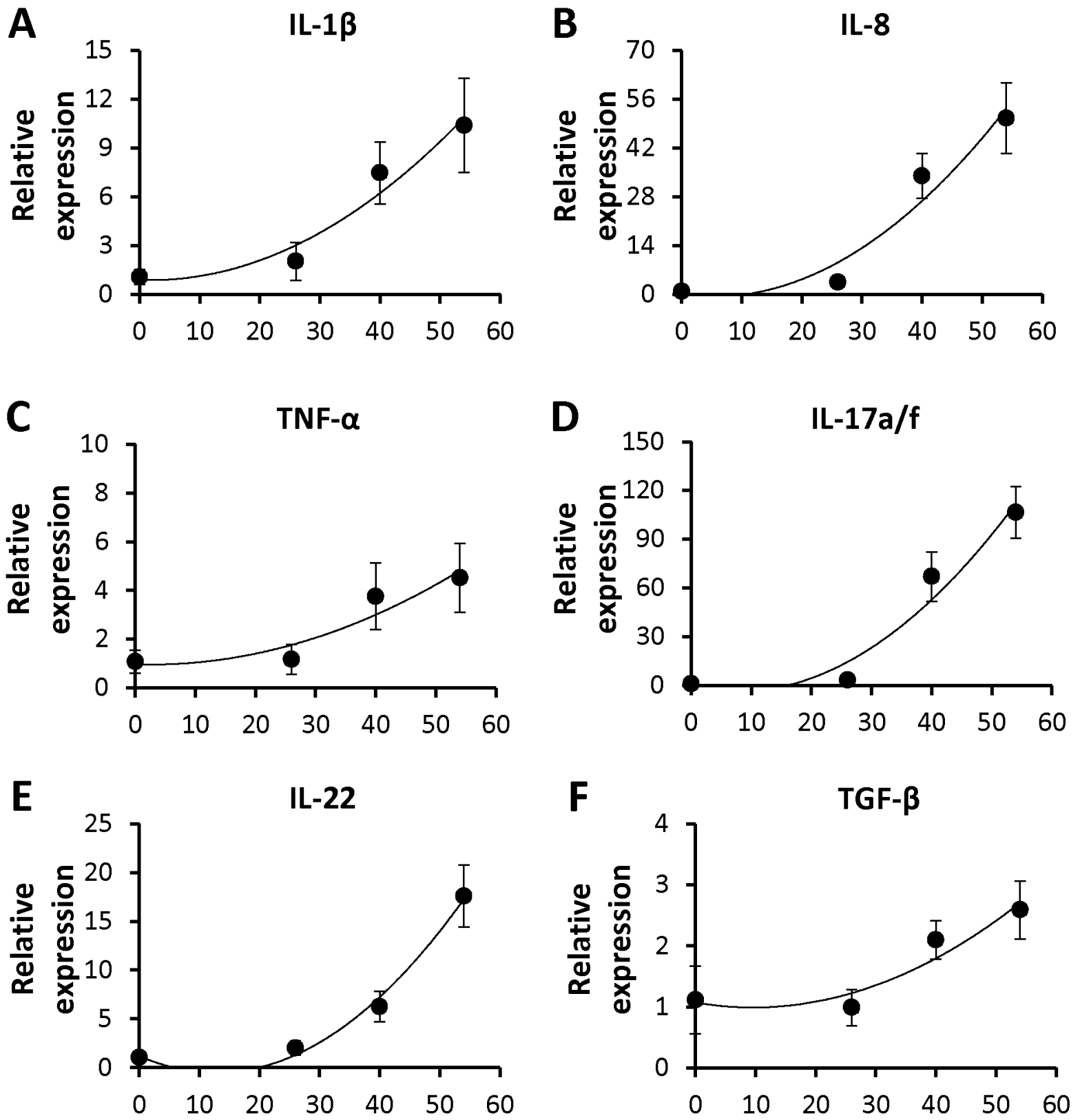